\title{
The Scientific Basis for Postoperative Respiratory Care
}

\author{
Richard D Branson MSc RRT FAARC
}

\author{
Introduction \\ Definitions and Incidence \\ Risk Factors \\ Intraoperative Mechanical Ventilation \\ Postoperative Respiratory Care \\ Incentive Spirometry \\ CPAP \\ Chest Physiotherapy \\ Positive Expiratory Pressure \\ Other Techniques \\ A PPC Bundle \\ Summary
}

\begin{abstract}
Postoperative pulmonary complications (PPCs) are common and expensive. Costs, morbidity, and mortality are higher with PPCs than with cardiac or thromboembolic complications. Preventing and treating PPCs is a major focus of respiratory therapists, using a wide variety of techniques and devices, including incentive spirometry, CPAP, positive expiratory pressure, intrapulmonary percussive ventilation, and chest physical therapy. The scientific evidence for these techniques is lacking. CPAP has some evidence of benefit in high risk patients with hypoxemia. Incentive spirometry is used frequently, but the evidence suggests that incentive spirometry alone has no impact on PPC. Chest physical therapy, which includes mechanical clapping and postural drainage, appears to worsen atelectasis secondary to pain and splinting. As with many past respiratory therapy techniques, the profession needs to take a hard look at these techniques and work to provide only practices based on good evidence. The idea of a PPC bundle has merit and should be studied in larger, multicenter trials. Additionally, intraoperative ventilation may play a key role in the development of PPCs and should receive greater attention. Key words: complications; postoperative pulmonary complications; incentive spirometry. [Respir Care 2013;58(11):1974-1984. () 2013 Daedalus Enterprises]
\end{abstract}

\section{Introduction}

Postoperative pulmonary complications (PPCs) following upper abdominal and thoracic surgery are the most

Mr Branson is affiliated with the Division of Trauma and Critical Care, Department of Surgery, University of Cincinnati, Cincinnati, Ohio.

Mr Branson presented a version of this paper at the 28th New Horizons in Respiratory Care Symposium, "The Scientific Basis for Respiratory common surgical complications. Additionally, PPCs are the leading cause of prolonged hospital stay, morbidity, and mortality in surgical patients. ${ }^{1-3}$ Simply stated by Smetana, "Postoperative pulmonary complications are common, serious, and expensive." ${ }^{4}$ Healthcare costs asso-

Care," at the AARC Congress 2012, held November 10-13, 2012, in New Orleans, Louisiana.

Mr Branson has disclosed relationships with Advanced Circulatory Systems, Covidien, Ikaria, and Hamilton Medical. 


\section{The Scientific Basis for Postoperative Respiratory Care}

ciated with the treatment of PPCs are 50\% greater than costs for treating postoperative cardiac complications. ${ }^{4-6}$ This finding has a number of explanations, including the complexity of the surgical procedures, the age of the patients, and the severity of the comorbidities.

The costs associated with PPCs are very high. In an analysis of data from the National Surgical Quality Improvement Program, the attributable cost of a PPC was over $\$ 52,000$ per patient. ${ }^{5}$ It is important to note that the National Surgical Quality Improvement Program data captures prolonged mechanical ventilation $(>48 \mathrm{~h}$ ), the need for intubation, and pneumonia as important PPCs. The finding of atelectasis on chest radiograph without any physiologic sequelae is not included in those data. Compared to other postoperative complications, including infection, thromboembolic (eg, pulmonary embolus), and cardiovascular complications, PPCs were associated with the greatest costs. Compared to patients who did not develop postoperative complications, patients with PPCs had an increased stay of 2 weeks.

This paper will focus on the use of respiratory therapy techniques for the treatment of PPCs. Given the financial impact of a single PPC, prevention and treatment are critical for the healthcare team, and the respiratory therapist plays an important role. However, it is important to understand the preoperative risk factors, intraoperative management, and interventions that may impact PPCs. These issues will be covered first, as a precursor for understanding the causes and best treatments for PPCs.

\section{Definitions and Incidence}

The reported incidence of PPCs ranges from 2-40\%.4-6 Reporting varies widely, as a consequence of surveillance and diagnostic criteria. In a general sense, a PPC is any event that occurs in the postoperative period that produces physiologic dysfunction or clinical disease. This unfortunately leads to wide interpretation. A PPC may be diagnosed based on symptoms (cough, fever, abnormal breath sounds), laboratory values (hypoxemia, leukocytosis), or radiographic criteria (atelectasis or infiltrate). As a result, a PPC can be defined as simply atelectasis on a chest radiograph or as respiratory failure necessitating intubation and mechanical ventilation. Clearly, the severity of these 2 complications is quite disparate, but each is recorded as a PPC. This complicates reporting the incidence

\footnotetext{
Correspondence: Richard D Branson MSc RRT FAARC, Division of Trauma and Critical Care, Department of Surgery, University of Cincinnati, 231 Albert Sabin Way, Cincinnati OH 45267-0558. E-mail: richard.branson@uc.edu.
}

DOI: $10.4187 /$ respcare.02832
Table 1. Postoperative Pulmonary Complications Reported in the Literature

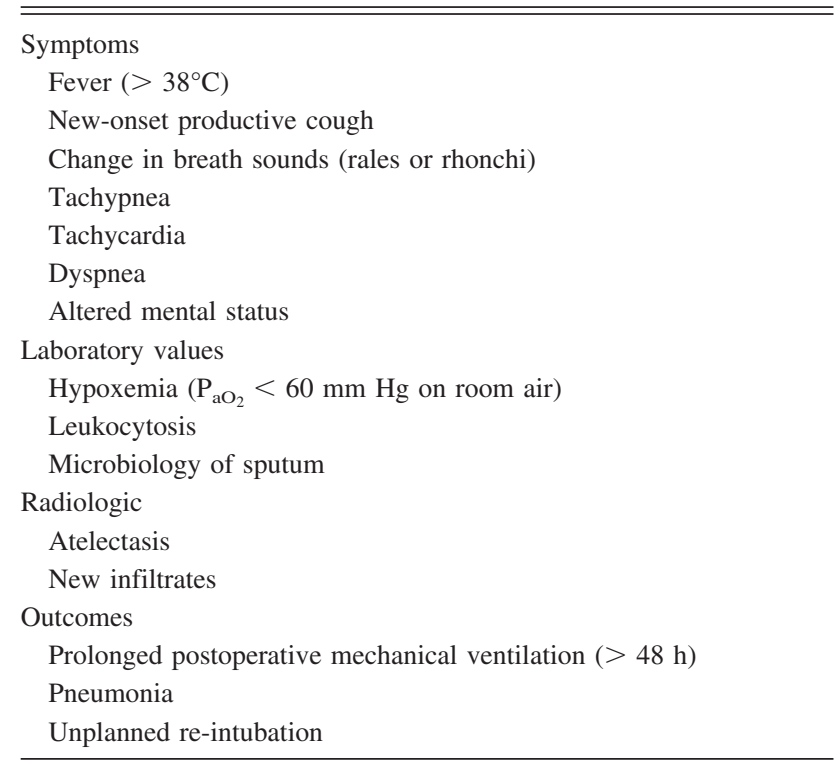

and importance of a PPC. Pulmonary embolus is an important PPC, but the pathology and treatment are quite different than those addressed by this paper. Table 1 lists the range of variables used to define a PPC.

Lawrence et al studied patients undergoing elective abdominal operations in a Veterans Affairs hospital and found that pulmonary complications occurred in $9.6 \%$ of patients. ${ }^{3}$ Brooks-Brunn ${ }^{7}$ suggested a more specific definition that includes at least 2 of the following findings documented at any time during the first 6 days following surgery: new cough and sputum production, abnormal breath sounds compared to baseline, temperature $>38^{\circ} \mathrm{C}$, chest radiograph demonstrating atelectasis or a new infiltrate, and physician documentation of atelectasis or pneumonia. This definition results in a more consistent reporting of the incidence of PPCs, but continues to rely on subjective evaluation of the patient by the caregiver.

The data from the National Surgical Quality Improvement Program suggest that the incidence of PPCs is 2.7$3.4 \%$ of patients undergoing non-cardiac surgery. ${ }^{5}$ That study categorized complications as minor or major using defined criteria. Interestingly, atelectasis alone was not listed as a PPC. The major respiratory complications included remaining on mechanical ventilation $>48$ hours, unplanned intubation, pneumonia, pulmonary embolism, or "other respiratory occurrence." Fleischman reported an incidence of $2.7 \%$ in a group of non-cardiac surgery patients: a rate similar to cardiac complications $(2.5 \%)$ in that same group. ${ }^{8}$ 


\section{The Scientific Basis for Postoperative Respiratory Care}

The actual incidence of important PPCs appears to be $2-5 \%$ in patients undergoing thoracic or upper abdominal surgery. The reported incidence varies with a given patient population (eg, COPD, the elderly) and type of procedure. Regardless, given the number of surgical procedures performed in the United States (over 4 million upper abdominal procedures per year) and the cost of a PPC, methods to prevent these complications are warranted.

\section{Risk Factors}

A number of risk factors have been identified that increase the likelihood of developing a PPC.9-18 These factors are listed in Table 2 as preoperative and intraoperative risks. Preoperatively, age $>50$ years, American Society of Anesthesiologists score $>2$, COPD, congestive heart failure, and smoking are among the greatest risk factors. The risk of age increases with each additional decade. Functional dependence is a significant risk factor, and refers to patients unable to perform the activities of daily living without assistance. Obstructive sleep apnea is new to the list, but results in only a minor increase in the risk of PPC. Current smokers have a higher risk than former smokers, whose risk is greater than never smokers. Interestingly, asthma and obesity do not appear to increase the risk substantially.

Intra-operatively, an upper abdominal incision is the greatest PPC risk factor. From a procedural perspective, open aortic repair, thoracic surgery, head and neck surgery, and neurosurgery are associated with increased risk. Surgery duration is also highly predictive; operations longer than 3 hours are associated with more frequent complications. ${ }^{9-15}$

Recently, a group at Massachusetts General Hospital looked specifically at the risk of reintubation following extubation in the operating room. They found similar risk factors as described above. By combining the risk factors and assigning a score to each risk factor, the authors were able to predict reintubation in a cohort of over 1,000 patients. The 11 point score includes; American Society of Anesthesiologists Score $\geq 3$, need for emergency surgery, care by a high-risk surgical service, patient history of congestive heart failure, and chronic pulmonary disease. Point values of $3,3,2,2$, and 1 were assigned to the respective items. It is important to note that this score predicts a severe PPC, notably the need for reintubation. ${ }^{16}$

\section{Intraoperative Mechanical Ventilation}

The paradigm change in mechanical ventilation for use of lung protection, most notably a target tidal volume of $6 \mathrm{~mL} / \mathrm{kg}$ of predicted body weight, has been slow to manifest in the operating room. In recent years, a number of authors have evaluated the impact of intraoperative tidal
Table 2. Risk Factors for Postoperative Pulmonary Complications

\begin{tabular}{l}
\hline Preoperative \\
Age $>50$ y: risk increases every decade after \\
American Society of Anesthesiologists Class $>2$ \\
Congestive heart failure \\
COPD \\
Obstructive sleep apnea \\
Cigarette use \\
Functional dependence (unable to perform activities of daily living \\
or requires assistance from caregiver or appliances) \\
Impaired sensorium \\
Corticosteroid use \\
Alcohol use \\
Intraoperative \\
Surgery longer than 3 h \\
Emergency surgery \\
Perioperative blood transfusion \\
General anesthesia \\
Use of neuromuscular blocking agents \\
Type of surgery \\
Open aortic resection \\
Head and neck surgery \\
Upper abdominal surgery \\
Thoracic surgery \\
Neurosurgery \\
High tidal volume \\
\hline (Data from references 10-18.) \\
\hline
\end{tabular}

volumes on postoperative lung function. ${ }^{17-19}$ Lellouche and colleagues found that an intraoperative tidal volume of $>10 \mathrm{~mL} / \mathrm{kg}$ predicted body weight in patients undergoing coronary artery bypass surgery was associated with postoperative organ dysfunction, morbidity, and mortality. ${ }^{19}$ Despite these findings, the use of a lung-protective approach in the operating room remains uncommon in patients with ${ }^{20}$ and without ${ }^{21}$ acute lung injury.

Severgnini et al studied 56 patients in a prospective, randomized, open-label trial of protective ventilation in patients undergoing $>2$ hours of open abdominal surgery. They found that using lower tidal volume, PEEP, and recruitment maneuvers resulted in significantly improved pulmonary function test results up to 5 days after surgery, fewer chest $\mathrm{x}$-ray findings, and improved Clinical Pulmonary Infection Score. ${ }^{22}$ These findings need to be replicated in a larger group of patients, but present unique options for preventing PPCs. Very recently, Futier et al demonstrated that the use of PEEP, recruitment, and low tidal volume during open abdominal surgery resulted in fewer PPCs, compared to tidal volume of $10-12 \mathrm{~mL} / \mathrm{kg}$ and no PEEP. ${ }^{23}$ The rates of postoperative atelectasis, pneumonia, and need for postoperative re-institution of venti- 
Table 3. Postoperative Complications in a Study Comparing Intraoperative Lung-Protective Ventilation (Low Tidal Volume, PEEP and Every 30 Min Recruitment Maneuvers) to High Tidal Volume and No PEEP

\begin{tabular}{|c|c|c|c|c|}
\hline Outcome & $\begin{array}{l}\text { High Tidal Volume } \\
\text { and No PEEP } \\
\text { no. }(\%)\end{array}$ & $\begin{array}{l}\text { Lung-Protective } \\
\text { Ventilation } \\
\text { no. }(\%)\end{array}$ & $\begin{array}{c}\text { Adjusted Relative Risk } \\
\text { Difference } \\
(95 \% \mathrm{CI})\end{array}$ & $P$ \\
\hline \multicolumn{5}{|c|}{ Pulmonary complications within $7 \mathrm{~d}$} \\
\hline Grade 1 or 2 & $30(15)$ & $25(12.5)$ & $0.67(0.39-1.16)$ & .16 \\
\hline Grade 3 or higher & $42(21)$ & $10(5)$ & $0.23(0.11-0.49)$ & $<.001$ \\
\hline Atelectasis & $34(17)$ & $13(6.5)$ & $0.37(0.19-0.73)$ & .004 \\
\hline Pneumonia & $16(8)$ & $3(1.5)$ & $0.19(0.05-0.66)$ & .009 \\
\hline Acute lung injury & $6(3)$ & $1(0.5)$ & $0.21(0.02-1.71)$ & .14 \\
\hline \multicolumn{5}{|c|}{ Need for mechanical ventilation } \\
\hline Invasive ventilation & $7(3.5)$ & $2(1)$ & $0.40(0.08-1.97)$ & .26 \\
\hline Noninvasive ventilation & $29(14.5)$ & $9(4.5)$ & $0.29(0.13-0.65)$ & .002 \\
\hline
\end{tabular}

lation were all increased 2- to 3-fold in the group that did not receive lung-protective ventilation (Table 3). These findings are compelling for the careful reconsideration of intraoperative management of ventilation. Intraoperative ventilation management may prevent PPCs and reduce costs by eliminating not only the complications but the required postoperative treatment.

\section{Postoperative Respiratory Care}

The combined impact of surgical trauma and anesthesia result in reduced lung volumes, respiratory muscle dysfunction, and atelectasis. ${ }^{24-26}$ Positioning, pain and pharmacologic agents can all worsen the reduction in lung volumes, characterized by substantial reductions in functional residual capacity and vital capacity. The development of atelectasis leads to hypoxemia and translocation of bacteria to the bloodstream, and may be important in creating the heterogeneous lung at risk for ventilator-induced lung injury. $27-28$

These physiologic findings led investigators to experiment with methods to increase lung volumes and improve cough postoperatively. These techniques are often referred to in the literature generically as postoperative physiotherapy, which includes coughing and deep breathing, incentive spirometry, percussion and postural drainage, CPAP, positive expiratory pressure (PEP), and other techniques. Save coughing and deep breathing, each of these techniques requires equipment and/or a healthcare provider.

A comparison of these studies by intervention is difficult, as in a few studies the control group received no intervention or coughing and deep breathing, in many studies there was no control group, and in some studies the control group received incentive spirometry. Often the studies have compared 2 or more techniques, alone or in combination. Finally, the outcomes have varied from physio- logic findings and radiographic appearance to more important outcomes such as the incidence of pneumonia or hospital stay.

\section{Incentive Spirometry}

Incentive spirometry was introduced by Bartlett and colleagues as a method to encourage deep breathing and sustained maximal inflations in postoperative patients. ${ }^{1,29}$ In the ensuing 40 years a litany of studies evaluating incentive spirometry for preventing PPC have been published. Two main areas of investigation have been pursued: incentive spirometry for PPC prevention following upper abdominal surgery, ${ }^{30-43}$ and incentive spirometry for PPC prevention following cardiac/thoracic surgery. ${ }^{44-60}$

Comparison of these studies is difficult, owing to the various study designs (randomized controlled trials and prospective trials), the comparators (none, chest physical therapy [CPT], CPAP, expiratory airway pressure), the frequency of interventions (eg, hourly, every 4 hours), the duration of each intervention (number of maneuvers, minutes of therapy), and the outcomes (radiographic atelectasis, gas exchange, pneumonia, pulmonary function). Of the studies that used PPCs as an outcome, 3 compared incentive spirometry with a control group of no intervention following upper abdominal surgery. ${ }^{31,34,37}$ While the most recent of these trials is 25 years old, none showed any advantage for incentive spirometry over no intervention. Incentive spirometry was compared to other interventions in 11 trials following upper abdominal surgery, and included incentive spirometry versus deep breathing exercises, intermittent positive-pressure breathing (IPPB), postural drainage, CPAP, PEP, and early ambulation. In several studies, patients received incentive spirometry and ambulation, CPAP, or PEP. In those trials, 6 studies found no differences between the groups, ${ }^{30-33,37,40} 3$ found incen- 
tive spirometry superior to the control intervention, ${ }^{39,41,42}$ and 2 found that both CPAP and IPPB were superior to incentive spirometry. ${ }^{34,36}$

Nine studies evaluated changes in pulmonary function with the use of incentive spirometry and other postoperative respiratory therapies following upper abdominal surgery. ${ }^{30,31-33,35,37,38.40,43}$ Schwieger et al compared incentive spirometry to no intervention in a group of low risk patients following laparoscopic cholecystectomy and found no differences in lung function. ${ }^{37}$ Minschaert and colleagues compared incentive spirometry to conventional physical therapy and found that incentive spirometry was associated with a faster recovery of tidal volume. ${ }^{43}$ Stock et al compared CPAP, incentive spirometry, and conservative therapy following upper abdominal surgery, and found that CPAP improved gas exchange and lung volumes, compared to incentive spirometry. ${ }^{38}$ Other studies in this category showed no advantage of incentive spirometry over other techniques with respect to restoration of lung volumes. $^{31-33,35,37,40}$

Studies comparing incentive spirometry for PPC prevention after cardiac/thoracic surgery also include a trial with no intervention as the control, ${ }^{48}$ and studies that compared incentive spirometry to other techniques. ${ }^{44,45,47,48,51,52,54,55,58,60}$ The majority of these trials reported no difference between incentive spirometry and the comparator. $44,47,48,51,52,54,58,60$ This creates one of the challenges in evaluating the evidence on incentive spirometry in PPC prevention. A randomized controlled trial with sufficient numbers should compare any of the techniques to a standard regimen of up and out of bed and early ambulation. Similar findings were seen in studies evaluating the impact on postoperative lung volumes; that is, the most common finding was no difference between incentive spirometry and the other intervention or no intervention. $44,47,51,59,60$

A recent paper by Agostini and colleagues compared incentive spirometry to "thoracic expansion exercises" in 180 patients following lung resection. ${ }^{60}$ All patients received postoperative breathing exercises, airway clearance, and early mobilization. There was no difference between the groups with respect to the fall in $\mathrm{FEV}_{1}$ on postoperative day 4 or the frequency of PPCs. They did, however, see a slight reduction in the frequency of PPCs in a cohort of "high risk" subjects using incentive spirometry. These patients were identified by age $\geq 75$ years, American Society of Anesthesiologists score $\geq 3$, COPD, smoking status, and body mass index $\geq 30 \mathrm{~kg} / \mathrm{m}^{2}$. Patients with 2 or more risk factors were deemed high risk.

Foraging these studies for problems and pearls is particularly perplexing. Incentive spirometry seems to be a common procedure performed by patients postoperatively all over the world. Yet the combined analysis of the literature has consistently failed to demonstrate any advantage of incentive spirometry in reducing PPCs or improving lung volumes postoperatively. In 2001, Overend and coworkers systematically reviewed the use of incentive spirometry for PPC prevention, and found that 10 of 11 studies showed no demonstrable impact of incentive spirometry. In fact, in the only remaining study incentive spirometry, deep breathing, and IPPB were equally more effective than no treatment in preventing PPCs following abdominal surgery. They concluded, "Presently, the evidence does not support the use of incentive spirometry for decreasing the incidence of PPCs following cardiac or upper abdominal surgery." 61

This report was followed by two reviews by Pasquina and colleagues in 2003 and 2006, both of which concluded that incentive spirometry, and, for that matter, other types of postoperative "physiotherapy" failed to impact the incidence of PPC. ${ }^{62,63}$ In their most recent review they evaluated 13 trials with a "no intervention" control group, and found that 9 trials with a total of 883 subjects failed to demonstrate any advantage with respect to PPC incidence. In 4 trials, which included 528 subjects, they found a positive impact on either pneumonia or atelectasis with incentive spirometry, coughing and deep breathing, IPPB, postural drainage, or directed cough. ${ }^{63}$ In 22 trials, which included 2,734 subjects, there was no control group, and no conclusion could be drawn. They wrote, "There are only a few trials that support the usefulness of prophylactic respiratory physiotherapy. The routine use of respiratory physiotherapy after abdominal surgery does not seem to be justified." 63

The two most recent Cochrane reviews of incentive spirometry for PPC prevention following upper abdominal surgery and cardiac/thoracic surgery also concluded that there is "no evidence" of benefit in either group. ${ }^{64,65}$ These findings are supported by the work of Agostini et al. ${ }^{66}$ Finally, a recent detailed systematic review by Carvalho and co-workers evaluated 30 studies that used incentive spirometry after upper abdominal surgery $(n=14)$ and cardiac/thoracic surgery $(n=16)$. These authors painstakingly reviewed the study designs, interventions, measured outcomes, and methodological rigor of each trial. They compared the impact of incentive spirometry on PPC and postoperative lung volumes in both upper abdominal surgery and cardiac/thoracic surgery. Most of the studies reviewed that favored incentive spirometry failed to report a sample size calculation, failed to randomize patients, and failed to have a control group, and therefore most likely bias the study outcomes. This excellent review concluded, "No evidence was found that supports the use of incentive spirometry in the management of surgical patients, and there is an urgent need for studies with adequate methodological designs to clarify the effect and to justify this technique." 67 
The perhaps surprising answer to the question "What is the evidence for incentive spirometry in postoperative prevention of PPC?" is that there is no high level evidence, and, in fact, the evidence does not support the routine use of incentive spirometry. If we were to assume that of the 4 million upper abdominal surgeries performed in the United States this year, each had an incentive spirometer and a healthcare provider encouraging and monitoring their progress, the current evidence suggests that the time and cost would be wasted. Rigorous studies of incentive spirometry in high risk patients, with adequate sample size and control groups, are sorely needed. Otherwise, the routine use of incentive spirometry should be abandoned.

\section{CPAP}

The use of mask CPAP for the treatment of postoperative hypoxemia, reduced functional residual capacity, and atelectasis was introduced in the late 1970s. ${ }^{68}$ The reported advantage of CPAP was that the lung volume facing the most drastic change postoperatively, functional residual capacity, could be restored passively without patient cooperation. That is to say, the application of a CPAP mask increases end-expiratory lung volume without deep breathing and might be associated with less pain and discomfort. CPAP also was reported to reduce the work of breathing and increase oxygenation. ${ }^{36,38}$

Nine studies have evaluated the use of CPAP to prevent PPCs in patients following upper abdominal surgery. ${ }^{36,38,68-74}$ As with incentive spirometry, the methodological differences in study design, outcomes, and comparators make comparisons difficult. All 9 were randomized trials, but the differences in equipment precluded blinding. Outcomes in these trials included the incidence of PPC in all 9; the incidence of pneumonia and atelectasis was measured in 4 of the trials. All of the trials included short periods of observation, and only 2 trials included follow-up evaluation beyond 1 week.

Of the 9 studies, only the work by Squadrone et al demonstrated a significant reduction in the incidence of PPC. ${ }^{74}$ The remaining 8 trials did not demonstrate a difference in the rate of PPC. ${ }^{36,38,68-73}$ This finding is in part due to the small number of subjects in each trial, potentially resulting in failure to demonstrate differences because the studies were underpowered. The Squadrone study also demonstrated a reduction in the rate of postoperative pneumonia in the group receiving CPAP. ${ }^{74}$ Pneumonia rates were unchanged in the remaining trials. A consistent positive finding in these studies is the improvement of oxygenation associated with CPAP. In a study using nasal CPAP following post operative care of cardiac bypass patients, hypoxemia was prevented and sleep was improved with the addition of CPAP. ${ }^{75}$
Ferreyra et al completed a systematic review and metaanalysis of these 9 trials, evaluating the impact on PPCs in patients undergoing upper abdominal surgery. ${ }^{76} \mathrm{By}$ combining trials, the number of patients available for analysis increased to 654 . Of these studies, the trials by Böhner ${ }^{72}$ and Squadrone ${ }^{74}$ represented over $400(63 \%)$ of the subjects. These trials used CPAP applied by face mask, nasal mask, mouthpiece, and helmet. The most common outcomes were radiographic demonstration of atelectasis and clinical diagnosis of pneumonia. It is important to note that none of the trials used the same criteria for diagnosing pneumonia.

By combining trials, Ferreyra and co-workers found that CPAP was associated with a significantly lower rate of PPCs than standard treatment, with a risk reduction of 0.34 (95\% CI 0.15-0.48). These findings suggest a numberneeded-to-treat to benefit of 14.2 (95\% CI 9.9-32.4). This systematic review demonstrated the effectiveness of CPAP in reducing the risk of PPCs, atelectasis, and pneumonia following upper abdominal surgery. Ferreyra et al also found that postoperative CPAP reduces the risk of endotracheal intubation. ${ }^{76}$ Total mortality in the 654 patients was too small to allow any meaningful comparisons. These data are the strongest evidence for any of the techniques used to prevent PPCs following upper abdominal surgery.

The trials used in this analysis included a number of different patient populations, and the impact of preoperative condition of the patients on the role of CPAP could not be evaluated. This analysis also suggested that CPAP should be applied postoperatively, immediately following the presentation of hypoxemia, and that CPAP should be applied continuously for 6 hours, with no interruption, until hypoxemia is abated.

Zarbock and colleagues published a trial of prophylactic nasal CPAP following elective cardiac surgery. This study of 500 subjects delivered nasal CPAP after extubation in the operating room (early extubation) or in the ICU (late extubation). Standard treatment (control) consisted of $10 \mathrm{~min}$ of intermittent nasal CPAP at $10 \mathrm{~cm} \mathrm{H}_{2} \mathrm{O}$ every $4 \mathrm{~h}$ or prophylactic nasal CPAP (intervention) at $10 \mathrm{~cm} \mathrm{H}_{2} \mathrm{O}$ for a minimum of 6 hours. They found that prophylactic nasal CPAP improved arterial oxygenation $\left(\mathrm{P}_{\mathrm{aO}_{2}} / \mathrm{F}_{\mathrm{IO}_{2}}\right)$ without hemodynamic consequences. PPCs, including hypoxemia $\left(\mathrm{P}_{\mathrm{aO}_{2}} / \mathrm{F}_{\mathrm{IO}_{2}}<100 \mathrm{~mm} \mathrm{Hg}\right)$, pneumonia, and reintubation rate, were reduced in the prophylactic CPAP group (12 of 232 patients vs 25 of 236 patients, respectively, $P=.03)$. Readmission rate to the ICU was also significantly lower in the nasal-CPAP-treated patients ( 7 of 232 patients vs 14 of 236 patients, respectively, $P=.03$ ).

The long-term administration of prophylactic nasal CPAP following cardiac surgery improved arterial oxygenation, reduced the incidence of PPCs, including pneumonia and reintubation, and reduced the ICU readmission rate. The authors concluded that nasal CPAP, administered 
prophylactically for 6 hours, reduced pulmonary morbidity following elective cardiac surgery. ${ }^{77}$

Recently, Barabagallo and colleagues found that CPAP provided by a helmet following thoracic surgery and lobectomy improved oxygenation, compared to a control group, for the first 24 hours. Patients receiving CPAP had a significantly shorter hospital stay, in comparison to control $(7 \pm 4 \mathrm{~d}$ and $8 \pm 13 \mathrm{~d}$, respectively, $P=.042)$. However, there were no differences in PPCs, ICU readmission, or mortality. This was a small study $(n=50)$ of high risk subjects. ${ }^{78}$

The utility of these data with respect to the scientific basis for postoperative respiratory care requires some interpretation. CPAP in high risk patients appears to improve oxygenation, increase functional residual capacity, and reduce PPCs. The widespread use of CPAP in patients without preoperative risk factors cannot be recommended.

\section{Chest Physiotherapy}

CPT and percussion and postural drainage are secretion mobilization methods that have been applied for PPC prevention and treatment for decades. CPT for treatment of PPCs owing to secretions obstructing small airways leading to atelectasis has some physiologic basis. However, the use of these techniques in the setting of atelectasis without retained airway secretions does not appear to have a rational cause and effect basis. This is particularly true in the face of upper abdominal and thoracic incisions, where performance of the treatment is likely to increase pain and splinting, and further impair lung function and cough. ${ }^{79}$

The literature on CPT must be read with care, as "postoperative physiotherapy" does not always equate to percussion and postural drainage. Just as frequently it includes coughing and deep breathing, incentive spirometry, and other techniques.

In an early study, Reines et al ${ }^{79}$ compared CPT to no CPT in a group of pediatric patients following cardiac surgery. The study goal was prevention of postoperative atelectasis. In this small study of 44 patients, CPT was associated with significantly more frequent $(P<.01)$ and more severe $(P<.01)$ atelectasis than no CPT. The authors concluded that the pain created by the procedure may have increased splinting and reduced lung volumes. The following year, Morran and colleagues published a study comparing CPT to no CPT in a group of patients following open cholecystectomy. They enrolled 102 patients, of whom 47 had no PPC, 29 had atelectasis, and 26 developed chest infection. Fifty-one patients did not receive CPT, of whom 11 developed atelectasis and 19 chest infection. Of the 51 patients who received CPT, 18 developed atelectasis and 7 chest infection. The authors concluded that routine prophylactic postoperative CPT significantly reduced the incidence of postoperative chest infection, ${ }^{80}$ Torrington et al compared traditional postoperative therapy with and without CPT in a group of 52 morbidly obese subjects following gastric bypass, and concluded that CPT caused patient discomfort, increased hospital cost, and failed to alter the incidence of PPCs. ${ }^{81}$

Christensen and colleagues ${ }^{82}$ studied 3 postoperative regimens of respiratory therapy on PPCs and lung function in high-risk patients. Fifty-one patients were randomized to conventional CPT alone; CPT and PEP; or CPT with both PEP and inspiratory resistance. Treatments were given twice daily by a physiotherapist, and self-administered between caregiver visits. The incidences of PPC were $71 \%$, $76 \%$, and $65 \%$ in the 3 groups. The incidence of PPCs requiring treatment with antibiotics, bronchodilators, or supplementary oxygen was lower in the group that received CPT plus PEP plus inspiratory resistance, as was the rate of pneumonia. However, owing to the small sample size, those differences were not statistically significant. The authors observed, "Insufficient self-administration of treatment was probably one of the causes of the overall high incidence of PPCs in this study." This study treated $\mathrm{CPT}$ as the control group, again making it difficult to know if eliminating CPT would have been just as successful.

Park and co-workers evaluated CPT and high-frequency chest-wall oscillation in a group of patients following lung resection. They found that high-frequency chest-wall oscillation improved gas exchange and forced vital capacity, but no outcomes were studied. ${ }^{83}$ This represents the conundrum in these trials: a new therapy is compared to a therapy with unproven benefit (CPT) and is shown to be similar of better. The importance of either cannot be judged without a control group.

Traditional physiotherapy, meaning chest percussion and vibration and postural drainage, has been ordered indiscriminately in the past. ${ }^{84}$ In the absence of retained secretions, the use of CPT to resolve atelectasis has no basis in fact. The current evidence, much of it old, demonstrates no role for CPT or high-frequency chest-wall oscillation in preventing PPCs. ${ }^{63}$

\section{Positive Expiratory Pressure}

PEP is a modification of the CPAP treatments used in the early 1980s. PEP does not require a continuous-flow gas source or supplemental oxygen, making it simpler and less expensive than CPAP. The use of PEP for PPC prevention has been reported sparingly in the literature. ${ }^{85-91}$

Munro et al found that using airway clearance after lung transplantation was not associated with a reduced incidence of respiratory infection or radiographic improvement of atelectasis. ${ }^{85}$ A Swedish study demonstrated that CPAP decreased the risk of respiratory distress requiring reintubation and the need for mechanical ventilation, com- 
Table 4. Components of the I COUGH Regimen

\begin{tabular}{|c|c|}
\hline Key Phrase & Explanation \\
\hline Incentive spirometry & $\begin{array}{l}\text { Educate the patient. } \\
\text { Keep the incentive spirometer within reach } \\
\text { and use it } 10 \text { times per hour: } 3-5 \text { breaths } \\
\text { per set. } \\
\text { Document incentive spirometry results } \\
\text { every } 4 \mathrm{~h} \text {. }\end{array}$ \\
\hline $\begin{array}{l}\text { Coughing and deep } \\
\text { breathing }\end{array}$ & $\begin{array}{l}\text { Encourage coughing and deep breathing } \\
\text { every } 2 \mathrm{~h} \text {. }\end{array}$ \\
\hline Oral care & Mouthwash and tooth brushing twice a day. \\
\hline Understanding & $\begin{array}{l}\text { Educate the patient and family regarding } \\
\text { postoperative care and expectations. }\end{array}$ \\
\hline $\begin{array}{l}\text { Get out of bed early } \\
\text { and often }\end{array}$ & $\begin{array}{l}\text { Walk once the day of the surgery and } \\
\text { thereafter at least } 3 \text { times a day. } \\
\text { Get out of bed to a chair } 3 \text { times a day for } \\
\text { meals. }\end{array}$ \\
\hline Head of bed elevation & Elevate the head of the bed to $\geq 30^{\circ}$. \\
\hline
\end{tabular}

pared with inspiratory resistive muscle training and PEP. 86 Additional studies have not demonstrated benefits of PEP in preventing or treating PPCs. The evidence does not support the routine use of PEP in treating PPCs.

\section{Other Techniques}

Use of intrapulmonary percussive ventilation has been reported in postoperative patients, but none of these studies specifically addressed the issue of PPCs. ${ }^{90-93}$ Similarly, IPPB has not shown to improve postoperative outcomes. ${ }^{65,94}$ In both instances the data are not available to support routine use.

\section{A PPC Bundle}

The success of the Institute for Healthcare Improvement ventilator-associated pneumonia bundle has changed ICU practice around the world. ${ }^{95}$ The concept of a group of related treatments and practices to reduce an important clinical burden has advantages to the search for a single silver bullet. This same approach was recently used by Cassiday et al in reducing PPCs. ${ }^{96}$ Using a system named I COUGH (for incentive spirometry, coughing and deep breathing, oral care, understanding, getting out of bed, and head of bed elevation), this group studied over 1,500 surgical cases, compared to a historical control group. See Table 4 for a more detailed description of the I COUGH methodology. The goal of this kind of trial is to develop a culture of education and improvement applied to patients and staff. To create and meet expectations with all stakeholders, the authors assembled educational materials, including pamphlets and a video, to educate patients and families, as well as encourage adherence to the protocol. As with any protocol, standardization tends to improve care through experience and reinforcement. The I COUGH methodology is simple and achievable, which is an important issue for implementation. The use of incentive spirometry in the treatment suite may or may not be important, but the authors suggested that the availability of incentive spirometry allows goal setting related to deep inspirations, and is helpful with patients who do not speak English.

Following all this praise, it is important to note that the study results did not reach statistical significance. However implementation of the program altered nursing practice (at the time of the protocol audits $80 \%$ of patients were in bed before the protocol was implemented vs $31 \%$ after). The incentive spirometer was within reach of the patient $53 \%$ of the time prior to the protocol and $77 \%$ of the time following implementation. The incidence of postoperative pneumonia fell from $2.6 \%$ to $1.6 \%$ after I COUGH was initiated. The incidence of unplanned intubations was $2 \%$ before I COUGH and 1.2\% after. Again, these changes were not statistically significant.

On the heels of bundles for VAP and sepsis, it is an attractive idea that a PPC bundle, involving a multidisciplinary team implementing simple measures, might improve outcomes and reduce costs. Further multicenter trials should follow this study to determine the impact.

\section{Summary}

The use of postoperative respiratory care is frequently indiscriminate and without support from the literature. Local tradition and experience dictate care, and caregiver time and consumables are used that may prove of no value. Of the techniques studied, CPAP in high risk patients with hypoxemia postoperatively has the greatest supporting evidence. Incentive spirometry, PEP, and other devices have either little support from the literature or have been shown not to be of value. CPT appears to have no role in reducing PPCs, despite the frequency with which it is ordered. A multidisciplinary PPC bundle is an attractive concept, but requires additional study.

\section{REFERENCES}

1. Bartlett RH, Brennan ML, Gazzaniga AB, Hanson EL. Studies on the pathogenesis and prevention of postoperative pulmonary complications. Surg Gynecol Obstet 1973;137(6):925-933.

2. Lawrence VA, Dhanda R, Hilsenbeck SG, Page CP. Risk of pulmonary complications after elective abdominal surgery. Chest 1996; 110(3):744-750.

3. Lawrence VA, Hilsenbeck SG, Mulrow CD, Dhanda R, Sapp J, Page $\mathrm{CP}$. Incidence and hospital stay for cardiac and pulmonary complications after abdominal surgery. J Gen Intern Med 1995;10(12):671678. 


\section{The Scientific Basis for Postoperative Respiratory Care}

4. Smetana GW. Postoperative pulmonary complications: an update on risk assessment and reduction. Cleve Clin J Med 2009;76(Suppl 4):S60-S65.

5. Dimick JB, Chen SL, Taheri PA, Henderson WG, Khuri SF, Campbell DA Jr. Hospital costs associated with surgical complications: a report from the private-sector National Surgical Quality Improvement Program. J Am Coll Surg 2004;199(4):531-537.

6. Hall RE, Ash AS, Ghali WA, Moskowitz MA. Hospital cost of complications associated with coronary artery bypass graft surgery. Am J Cardiol 1997;79(12):1680-1682.

7. Brooks-Brunn JA. Predictors of postoperative pulmonary complications following abdominal surgery. Chest 1997;111(3):564-571.

8. Fleischmann KE, Goldman L, Young B, Lee TH. Association between cardiac and noncardiac complications in patients undergoing noncardiac surgery: outcomes and effects on length of stay. Am J Med 2003;115(7):515-520.

9. Fry DE, Pine M, Jordan HS, Elixhauser A, Hoaglin DC, Jones B, et al. Combining administrative and clinical data to stratify surgical risk. Ann Surg 2007;246(5):875-885.

10. Smetana GW, Lawrence VA, Cornell JE; American College of Physicians. Preoperative pulmonary risk stratification for noncardiothoracic surgery: systematic review for the American College of Physicians. Ann Intern Med 2006;144(8):581-595.

11. Johnson RG, Arozullah AM, Neumayer L, Henderson WG, Hosokawa P, Khuri SF. Multivariable predictors of postoperative respiratory failure after general and vascular surgery: results from the patient safety in surgery study. J Am Coll Surg 2007;204(6):11881198.

12. Qaseem A, Snow V, Fitterman N, Hornbake ER, Lawrence VA, Smetana GW, et al. Risk assessment for and strategies to reduce perioperative pulmonary complications for patients undergoing noncardiothoracic surgery: a guideline from the American College of Physicians. Ann Intern Med 2006;144(8):575-580.

13. Lawrence VA, Cornell JE, Smetana GW; American College of Physicians. Strategies to reduce postoperative pulmonary complications after noncardiothoracic surgery: systematic review for the American College of Physicians. Ann Intern Med 2006;144(8):596-608.

14. Hwang D, Shakir N, Limann B, Sison C, Kalra S, Shulman L, et al. Association of sleep-disordered breathing with postoperative complications. Chest 2008;133(10):1128-1134.

15. Arozullah AM, Daley J, Henderson WG, Khuri SF. Multifactorial risk index for predicting postoperative respiratory failure in men after major noncardiac surgery. The National Veterans Administration Surgical Quality Improvement Program. Ann Surg 2000;232(3): 242-253.

16. Brueckmann B, Villa-Uribe JL, Bateman BT, Grosse-Sundrup M, Hess DR, Schlett CL, Eikermann M. Development and validation of a score for prediction of postoperative respiratory complications. Anesthesiology 2013;118(6):1276-1285.

17. Fernández-Pérez ER, Sprung J, Afessa B, Warner DO, Vachon CM, Schroeder DR, et al. Intraoperative ventilator settings and acute lung injury after elective surgery: a nested case control study. Thorax 2009;64(2):121-127.

18. Licker M, Diaper J, Villiger Y, Spiliopoulos A, Licker V, Robert J, Tschopp JM. Impact of intraoperative lung-protective interventions in patients undergoing lung cancer surgery. Crit Care 2009;13(2): $\mathrm{R} 41$.

19. Lellouche F, Dionne S, Simard S, Bussières J, Dagenais F. High tidal volumes in mechanically ventilated patients increase organ dysfunction after cardiac surgery. Anesthesiology 2012;116(5):1072-1082.

20. Chaiwat O, Vavilala MS, Philip S, Malakouti A, Neff MJ, Deem S, et al. Intraoperative adherence to a low tidal volume ventilation strategy in critically ill patients with preexisting acute lung injury. $\mathrm{J}$ Crit Care 2011;26(2):144-149.
21. Hess DR, Kondili D, Burns E, Bittner EA, Schmidt UH. A 5-year observational study of lung-protective ventilation in the operating room: a single-center experience. J Crit Care. 2013;28(4):533.e9533.e15.

22. Severgnini P, Selmo G, Lanza C, Chiesa A, Frigerio A, Bacuzzi A, et al. Protective mechanical ventilation during general anesthesia for open abdominal surgery improves postoperative pulmonary function. Anesthesiology 2013;118(6):1307-1321.

23. Futier E, Constantin JM, Paugam-Burtz C, Pascal J, Eurin M, Neuschwander A, et al. A trial of intraoperative low-tidal-volume ventilation in abdominal surgery. N Engl J Med 2013;369(5):428437.

24. Hedenstierna G, Edmark L. The effects of anesthesia and muscle paralysis on the respiratory system. Intensive Care Med 2005;31(11): 1327-1335.

25. Saski N, Meyer MJ, Eikermann M. Postoperative respiratory muscle dysfunction. Anesthesiology 2013;118(4):961-978.

26. Nicholson DJ, Kowalski SE, Hamilton GA, Meyers MP, Serrette C, Duke PC. Postoperative pulmonary function in coronary artery bypass graft surgery patients undergoing early tracheal extubation: a comparison between short-term mechanical ventilation and early extubation. J Cardiothorac Vasc Anesth 2002;16(1):27-31.

27. Duggan M, McCaul CL, McNamara PJ, Engelberts D, Ackerley C, Kavanagh BP. Atelectasis causes vascular leak and lethal right ventricular failure in uninjured rat lungs. Am J Respir Crit Care Med 2003;167(12):1633-1640.

28. van Kaam AH, Lachmann RA, Herting E, De Jaegere A, van Iwaarden F, Noorduyn LA, et al. Reducing atelectasis attenuates bacterial growth and translocation in experimental pneumonia. Am J Respir Crit Care Med 2004;169(30):1046-1053.

29. Bartlett RH, Gazzaniga AB, Geraghty TR. Respiratory maneuvers to prevent postoperative pulmonary complications. A critical review. JAMA 1973;224(7):1017-1021.

30. O'Connor M, Tattersall MP, Carter JA. An evaluation of the incentive spirometer to improve lung function after cholecystectomy. Anaesthesia 1988;43(9):785-787.

31. Hall JC, Tarala R, Harris J, Tapper J, Christiansen K. Incentive spirometry versus routine chest physiotherapy for prevention of pulmonary complications after abdominal surgery. Lancet 1991; 337(8747):953-956.

32. Hall JC, Tarala RA, Tapper J, Hall JL. Prevention of respiratory complications after abdominal surgery: a randomized clinical trial. BMJ 1996;312(7024):148-153.

33. Cattano D, Altamirano A, Vannucci A, Melnikov V, Cone C, Hagberg CA. Preoperative use of incentive spirometry does not affect postoperative lung function in bariatric surgery. Transl Res 2010; 156(5):265-272.

34. Celli BR, Rodriguez KS, Snider GL. A controlled trial of intermittent positive pressure breathing, incentive spirometry, and deep breathing exercises in preventing pulmonary complications after abdominal surgery. Am Rev Respir Dis 1984;130(1):12-15.

35. Kundra P, Vitheeswaran M, Nagappa M, Sistla S. Effect of preoperative and postoperative incentive spirometry on lung functions after laparoscopic cholecystectomy. Surg Laparosc Endosc Percutan Tech 2010;20(3):170-172.

36. Ricksten SE, Bengtsson A, Soderberg C, Thorden M, Kvist H. Effects of periodic positive airway pressure by mask on postoperative pulmonary function. Chest 1986;89(6):774-781.

37. Schwieger I, Gamulin Z, Forster A, Meyer P, Gemperle M, Suter PM. Absence of benefit of incentive spirometry in low-risk patients undergoing elective cholecystectomy. A controlled randomized study. Chest 1986;89(5):652-656. 


\section{The Scientific Basis for Postoperative Respiratory Care}

38. Stock MC, Downs JB, Gauer PK, Alster JM, Imrey PB. Prevention of postoperative pulmonary complications with CPAP, incentive spirometry, and conservative therapy. Chest 1985;87(2):151-157.

39. Craven JL, Evans GA, Davenport PJ, Williams RH. The evaluation of the incentive spirometer in the management of postoperative pulmonary complications. Br J Surg 1974;61(10):793-797.

40. Lyager S, Wernberg M, Rajani N, Bøggild-Madsen B, Nielsen L, Nielsen HC, et al. Can postoperative pulmonary conditions be improved by treatment with the Bartlett-Edwards incentive spirometer after upper abdominal surgery? Acta Anaesthesiol Scand 1979;23(4): 312-319.

41. Dohi S, Gold MI. Comparison of two methods of postoperative respiratory care. Chest 1978;73(5):592-595.

42. Jung R, Wight J, Nusser R, Rosoff L. Comparison of three methods of respiratory care following upper abdominal surgery. Chest 1980; 78(1):31-35.

43. Minschaert M, Vincent JL, Ros AM, Kahn RJ. Influence of incentive spirometry on pulmonary volumes after laparotomy. Acta Anaesthesiol Belg 1982;33(3):203-209.

44. Crowe JM, Bradley CA. The effectiveness of incentive spirometry with physical therapy for high-risk patients after coronary artery bypass surgery. Phys Ther 1997;77(3):260-268.

45. Haeffener MP, Ferreira GM, Barreto SS, Arena R, Dall'Ago P. Incentive spirometry with expiratory positive airway pressure reduces pulmonary complications, improves pulmonary function and 6-minute walk distance in patients undergoing coronary artery bypass graft surgery. Am Heart J 2008;156(6):901-908.

46. Matte P, Jacquet L, Van Dyck M, Goenen M. Effects of conventional physiotherapy, continuous positive airway pressure and non-invasive ventilatory support with bilevel positive airway pressure after coronary artery bypass grafting. Acta Anaesthesiol Scand 2000;44(1):7581.

47. Oikkonen M, Karjalainen K, Kähärä V, Kuosa R, Schavikin L. Comparison of incentive spirometry and intermittent positive pressure breathing after coronary artery bypass graft. Chest 1991;99(1):60-65.

48. Yánez-Brage I, Pita-Fernández S, Juffé-Stein A, Martínez-González U, Pértega-Díaz S, Mauleón-García A. Respiratory physiotherapy and incidence of pulmonary complications in off-pump coronary artery bypass graft surgery: an observational follow-up study. BMC Pulm Med 2009;(9):36.

49. Gosselink R, Schrever K, Cops P, Witvrouwen H, De Leyn P, Troosters $\mathrm{T}$, et al. Incentive spirometry does not enhance recovery after thoracic surgery. Crit Care Med 2000;28(3):679-683.

50. Dias CM, de Oliveira R, Oliveira JF, Lopes AJ, Silveira de Menezes SL, Guimarães FS. Three physiotherapy protocols: effects on pulmonary volumes after cardiac surgery. J Bras Pneumol 2011;37(1): 54-60.

51. Jenkins SC, Soutar SA, Loukota JM, Johnson LC, Moxham J. Physiotherapy after coronary artery surgery: are breathing exercises necessary? Thorax 1989;44(8):634-639.

52. Stock MC, Downs JB, Cooper RB, Lebenson IM, Cleveland J, Weaver $\mathrm{DE}$, et al. Comparison of continuous positive airway pressure, incentive spirometry, and conservative therapy after cardiac operations. Crit Care Med 1984;12(11):969-972.

53. Vilaplana J, Sabaté A, Ramon R, Gasolibe V, Villalonga R. Ineffectiveness of incentive spirometry as coadjuvant of conventional physiotherapy for the prevention of postoperative respiratory complications after thoracic and esophageal surgery. Rev Esp Anestesiol Reanim 1990;37(6):321-325.

54. Gale GD, Sanders DE. Incentive spirometry: its value after cardiac surgery. Can Anesth Soc J 1980;27(5):475-480.

55. Iverson LI, Ecker RR, Fox HE, May IA. A comparative study of IPPB, the incentive spirometer, and blow bottles: the prevention of atelectasis following cardiac surgery. Ann Thorac Surg 1978;25(3): 197-200.

56. Romanini W, Muller AP, Carvalho KA, Olandoski M, Faria-Neto JR, Mendes FL, et al. The effects of intermittent positive pressure and incentive spirometry in the postoperative of myocardial revascularization. Arq Bras Cardiol 2007;89(2):94-99.

57. Weiner P, Man A, Weiner M, Rabner M, Waizman J, Magadle R, et al. The effect of incentive spirometry and inspiratory muscle training on pulmonary function after lung resection. J Thorac Cardiovasc Surg 1997;113(3):552-557.

58. Dull JL, Dull WL. Are maximal inspiratory breathing exercises or incentive spirometry better than early mobilization after cardiopulmonary bypass? Phys Ther 1983;63(5):655-659.

59. Renault JA, Costa-Val R, Rosseti MB, Houri Neto M. Comparison between deep breathing exercises and incentive spirometry after CABG surgery. Rev Bras Cir Cardiovasc 2009;24(2):165-172.

60. Agostini P, Naidu B, Cieslik H, Steyn R, Rajesh PB, Bishay E, et al. Effectiveness of incentive spirometry in patients following thoracotomy and lung resection including those at high risk for developing pulmonary complications. Thorax 2013;68(6):580-585.

61. Overend TJ, Anderson CM, Lucy SD, Bhatia C, Jonsson BI, Timmermans C. The effect of incentive spirometry on postoperative pulmonary complications: a systematic review. Chest 2001;120(3): 971-978.

62. Pasquina $\mathrm{P}$, Tramèr MR, Walder $\mathrm{B}$. Prophylactic respiratory physiotherapy after cardiac surgery: systematic review. BMJ 2003; 327(7428): 1379.

63. Pasquina $\mathrm{P}$, Tramèr MR, Granier JM, Walder B. Respiratory physiotherapy to prevent pulmonary complications after abdominal surgery: a systematic review. Chest 2006 Dec;130(6):1887-1899.

64. Guimarães MM, El Dib R, Smith AF, Matos D. Incentive spirometry for prevention of postoperative pulmonary complications in upper abdominal surgery. Cochrane Database Syst Rev 2009;(3):CD006058.

65. Freitas ER, Soares BG, Cardoso JR, Atallah ÁN. Incentive spirometry for preventing pulmonary complications after coronary artery bypass graft. Cochrane Database Syst Rev 2012;(9):CD004466.

66. Agostini P, Calvert R, Subramanian H, Naidu B. Is incentive spirometry effective following thoracic surgery? Interact Cardiovasc Thorac Surg 2008;7(2):297-300.

67. Carvalho CR, Paisani DM, Lunardi AC. Incentive spirometry in major surgeries: a systematic review. Rev Bras Fisioter 2011;15(5): 343-350.

68. Anderes C, Anderes U, Gasser D, Dittmann M, Turner J, Brennwald $\mathrm{J}$, et al. Postoperative spontaneous breathing with CPAP to normalize late postoperative oxygenation. Intensive Care Med 1979;5(1): $15-21$.

69. Carlsson C, Sonden B, Thylen U. Can postoperative continuous positive airway pressure (CPAP) prevent pulmonary complications after abdominal surgery? Intensive Care Med 1981;7(4):225-229.

70. Lotz P, Heise U, Schäffer J, Wollinsky KH. [The effect of intraoperative PEEP ventilation and postoperative CPAP breathing on postoperative lung function following upper abdominal surgery]. Anaesthesist 1984;33(4):177-188. Article in German.

71. Lindner KH, Lotz P, Ahnefeld FW. Continuous positive airway pressure effect on functional residual capacity, vital capacity and its subdivisions. Chest 1987;92(1):66-70.

72. Böhner H, Kindgen-Milles D, Grust A, Buhl R, Lillotte WC, Müller BT, et al. Prophylactic nasal continuous positive airway pressure after major vascular surgery: results of a prospective randomized trial. Langenbecks Arch Surg 2002;387(1):21-26.

73. Denehy L, Carroll S, Ntoumenopoulos G, Jenkins S. A randomized controlled trial comparing periodic mask CPAP with physiotherapy after abdominal surgery. Physiother Res Int 2001;6(4):236-250. 


\section{The Scientific Basis for Postoperative Respiratory Care}

74. Squadrone V, Coha M, Cerutti E, Schellino MM, Biloino P, Occella P, et al.; Piedmont Intensive Care Units Network (PICUN). Continuous positive airway pressure for treatment of postoperative hypoxemia: a randomized controlled trial. JAMA 2005;293(5):589-595.

75. Drummond GB, Stedul K, Kingshott R, Rees K, Nimmo AF, Wraith P, Douglas NJ. Automatic CPAP compared with conventional treatment for episodic hypoxemia and sleep disturbance after major abdominal surgery. Anesthesiology 2002;96(4):817-826.

76. Ferreyra GP, Baussano I, Squadrone V, Richiardi L, Machiaro G, Del Sorbo L, et al. Continuous positive airway pressure for treatment of respiratory complications after abdominal surgery. Ann Surg 2008; 247(4):617-626.

77. Zarbock A, Mueller E, Netzer S, Gabriel A, Feindt P, KindgenMilles D. Prophylactic nasal continuous positive airway pressure following cardiac surgery protects from postoperative pulmonary complications: a prospective, randomized, controlled trial in 500 patients. Chest 2009;135(5):1252-1259.

78. Barbagallo M, Ortu A, Spadini E, Salvadori A, Ampollini L, Internullo E, et al. Prophylactic use of helmet CPAP after pulmonary lobectomy: a prospective randomized controlled study. Respir Care 2012;57(9):1418-1424.

79. Reines HD, Sade RM, Bradford BF, Marshall J. Chest physiotherapy fails to prevent postoperative atelectasis in children after cardiac surgery. Ann Surg 1982;195(4):451-455.

80. Morran CG, Finlay IG, Mathieson M, McKay AJ, Wilson N, McArdle CS. Randomized controlled trial of physiotherapy for postoperative pulmonary complications. Br J Anaesth 1983;55(11):1113-1117.

81. Torrington KG, Sorenson DE, Sherwood LM. Postoperative chest percussion with postural drainage in obese patients following gastric stapling. Chest 1984;86(7):891-895.

82. Christensen EF, Schultz P, Jensen OV, Egebo K, Engberg M, Grøn I, Juhl B. Postoperative pulmonary complications and lung function in high-risk patients: a comparison of three physiotherapy regimens after upper abdominal surgery in general anesthesia. Acta Anaesthesiol Scand 1991;35(2):97-104.

83. Park H, Park J, Woo SY, Yi YH, Kim K. Effect of high-frequency chest wall oscillation on pulmonary function after pulmonary lobectomy for non-small cell lung cancer. Crit Care Med 2012;40(9): 2583-2589.

84. Alexander E, Weingarten S, Mohsenifar Z. Clinical strategies to reduce utilization of chest physiotherapy without compromising patient care. Chest 1996;110(2):430-432.

85. Munro PE, Button BM, Bailey M, Whitford H, Ellis SJ, Snell GI Should lung transplant recipients routinely perform airway clear- ance techniques? A randomized trial. Respirology 2008;13(7):10531060.

86. Fagevik Olsén M, Wennberg E, Johnsson E, Josefson K, Lönroth H, Lundell L. Randomized clinical study of the prevention of pulmonary complications after thoracoabdominal resection by two different breathing techniques. Br J Surg 2002;89(10):1228-1234.

87. Westerdahl E, Lindmark B, Almgren SO, Tenling A. Chest physiotherapy after coronary artery bypass graft surgery: a comparison of three different deep breathing techniques. J Rehabil Med 2001;33(2): 79-84.

88. Ingwersen UM, Larsen KR, Bertelsen MT, Kiil-Nielsen K, Laub M, Sandermann J, et al. Three different mask physiotherapy regimens for prevention of post-operative pulmonary complications after heart and pulmonary surgery. Intensive Care Med 1993;19(5):294-298.

89. Frølund L, Madsen F. Self-administered prophylactic postoperative positive expiratory pressure in thoracic surgery. Acta Anaesthesiol Scand 1986;30(5):381-385.

90. Reper P, van Looy K. Chest physiotherapy using intrapulmonary percussive ventilation to treat persistent atelectasis in hypoxic patients after smoke inhalation. Burns 2013;39(1):192-193.

91. Dimassi S, Vargas F, Lyazidi A, Roche-Campo F, Dellamonica J, Brochard L. Intrapulmonary percussive ventilation superimposed on spontaneous breathing: a physiological study in patients at risk for extubation failure. Intensive Care Med 2011;37(8):1269-1276.

92. Gatani T, Martucci N, La Rocca A, La Manna C, Scognamiglio F, Salvi R, Rocco G. Management of localized pneumothoraces after pulmonary resection with intrapulmonary percussive ventilation. Ann Thorac Surg 2010;90(5):1658-1661.

93. Yen Ha TK, Bui TD, Tran AT, Badin P, Toussaint M, Nguyen AT. Atelectatic children treated with intrapulmonary percussive ventilation via a face mask: clinical trial and literature overview. Pediatr Int 2007;49(4):502-507.

94. Schuppisser JP, Brandli O, Meli U. Postoperative intermittent positive pressure breathing versus physiotherapy. Am J Surg 1980;140(5): 682-686.

95. Institute for Healthcare Improvement. Implement the IHI ventilator bundle. Last modified August 2011. http://www.ihi.org/knowledge/ Pages/Changes/ImplementtheVentilatorBundle.aspx. Accessed August 27, 2013.

96. Cassiday MR, Rosenkranz P, McCabe K, Rosen J, McAneny DA. I COUGH: reducing postoperative pulmonary complications with a multidisciplinary patient care program. JAMA Surg 2013;148(8): 740-745. 